\title{
Using human-powered products for sustainability and health: benefits, challenges, and opportunities
}

\author{
Hyunjae Daniel Shin, Amin Al-Habaibeh* and Jose L. Casamayor \\ Innovative and Sustainable Built Environment Technologies (iSBET) research group \\ Product Design \\ School of Architecture Design and the Built Environment, \\ Nottingham Trent University, UK
}

${ }^{*}$ Corresponding Author: Professor Amin Al-Habaibeh, Nottingham Trent University, NG1 4BU, email: amin.al-habaibeh@ntu.ac.uk

\begin{abstract}
This paper presents a novel research work on the potential benefits of using, a unique and sustainable energy source - the human-power. The paper discusses the benefits and the practicality of using human-power as a domestic energy source to power electrical and electronic devices and explores the benefit of its use in a more diverse perspective for possible change in behaviour and energy savings for improved sustainability in the society. The economic and sustainability gains of using Human-Powered Products (HPPs) are investigated. Two studies have been conducted, the first is a study which involves assessing the environmental impact of a human-powered products via Life Cycle Assessment (LCA); and the second is a case study called Home User Study (HUS), where the technology is experimentally tested. The humanpowered system is used to explore the real benefits and life-cycle analysis towards assessing the sustainability of such products. The Home User Study (HUS) has been conducted to explore the in-situ use of human-powered systems using a new prototype that has been built and deployed. The study has used a monitoring device to measure the outcome of the interaction between the user and human-powered products. The results interestingly have revealed various other forms of benefits beyond renewable energy that could add extra motives for using human-powered products, such as health benefits. The paper also puts an emphasis on the opportunity of using Human-Powered Products which can be perceived as a great viable solution against counter measuring social issues such as physical inactivity and increasing sedentary behaviour. The results of the theoretical study indicate that Human-Powered Products (HPP) do not offer significant financial savings. The results of the HUS indicate that using human-powered products for health prospective outweigh the benefit gained from the prospective of energy savings and renewable energy. Based on the findings of this study, the paper suggests an approach that shows how the implementation of Human-powered systems could provide the opportunity to
\end{abstract}


sustainable energy generation and energy savings, but in all cases they can be retained through a motivational drive in improving the health benefit via encouraging physical activities.

\section{Key words}

Sustainability, Human-powered Devices, Renewable Energy, Energy Cost, Public Health.

\section{Introduction}

Renewable energy has been attracting significant attention in recent years to reduce pollution and at the same time to provide sustainable and clean source of energy. The most common types of renewable energy are solar, wind, tidal, geothermal and wave. These developments therefore promote new technologies of renewable energy production as well as encourage a new culture of energy consumption. One of the sustainable and renewable energy resource that has not been recognised is the use of human-power. This paper discusses the implications of using human-power as a domestic energy source to power or control electrical devices and the expected impact towards sustainability.

In developing countries where there is a lack of energy and comfort, people use human-power as a sustainable way to achieve many daily tasks at home and work. Physical activities and humanpower normally include activities such as walking for long distances for water access, cycling to work, collecting animal waste as fuel for daily cooking, and grinding grains. This societal lifestyle does not depend upon the need of using fossil fuel and hence carbon emission; and at the same time, keeps people physically active and prevents obesity. In developed countries, on the other hand, people are surrounded by modern technologies and transportation, which may avail reducing the required physical activities and consumes more energy per capita. This is causing, not only pollution and carbon emission, but also causing physical inactivity, obesity epidemic and many public health problems.

As recently as 150 years ago, human-powered products (HPP) were the norm in every nation, e.g. hand crank grinder, bicycle, pedal-powered lathe and sewing machine. However, with the development and wide-spreading of the electro-mechanical motors and electricity, everyday 'products' have evolved significantly. Simultaneously, using human-power for powering such products has also gradually diminished (Dean, 2008). Technologies have been constantly evolving and through these advances, our life styles have become notably more efficient. The ever-increasing efficiency of products offers a convenience that less and less physical human effort is required to carry out a task. However, will it be possible to abandon these new accustomed efficiencies and use the human-power once again to power electrical devices or perhaps create new practice? The bicycle is a great example of a means of utilising relevant 
human-power that allows user to exercise, transport, and save consumption of conventional energy at the same time. If, for example, we can design human powered systems to become more 'entertaining' or 'a necessity', this may be an optimal method for encouraging new behaviour of using human-power, and hence reduce energy consumption.

In the past two decades, there has been an exponential and significant increase in the number of consumer electronics and portable electronic devices providing increased mobility; and new applications of ICT (Information and Communication Technology) related devices such as mobile phones (Bertoldi and Atanasiu, 2007). The increase in electricity consumption from using consumer electronics such as televisions, home computing, tablet PCs and other power supply units outstands as their energy usage are still at an incremental rate (DECC, 2011). Humanpowered products (HPP), has been perceived in recent research as alternatives to mobile battery running electronic products (Jansen, 2011; Jansen and Stevels, 1999), and a generator to power electronics in rural communicties (Louie et al., 2010). Scholars have often looked at parasitic ways to harvest the energy from daily human movements such as using children's play energy (Pandian, 2004), using walking energy to power implantable medical devices (Jia and Liu, 2009; Rao et al., 2014), and using body heat to power wearable computing devices (Starner, 1996). Such products are considered as one solution to curb the energy related problems caused by the increase in Energy using Products (EuP). In other words, EuP can be powered by human-power and therefore no longer relies on the use of electricity from the grid. Another aspect to humanpower that can be worthy of attention is the availability and portability of energy generation. Despite the rapid growth in wireless and portable electronics, power storage technologies of EuP have been lagging. It is assumed that its power storage capacity or energy density will never satisfy its frequency of usage. Thus, against these proliferated usages of portable electronics, human-power becomes a more viable and practical solution.

Arjen Jansen (2011) has described the advantage of using human-powered devices. Three benefits of a HPP from eco-design stand point, and they are (Jansen and Stevels, 2006, p.499): (1) material benefit as they do not consume energy from non-renewable resources during the use-phase of the life cycle; (2) immaterial benefit in the convenience of having power available all the time; and (3) emotional benefit as human-powered products enhance the quality of life by making the consumer feel environmentally pro-active.

However, the frequency of HPP use has not been well investigated, especially in understanding the motivational factor and the links to physical activities. Considering the rapid growth of efficiency in many electronics, it is realised that ever decreasing wattage of EuP power use makes the feasibility of human-power may perceive more practical. This would mean that the physical activities needed in generating the required power and performance of using stored energy will likely be reduced over the years. For example, a study conducted by Louie et al. (2010) shows that 80 percent of full voltage of a mobile phone can be charged in $1 \mathrm{~h}$ (hour) using 
the small human-powered generator. The key question that the authors would like to address in this paper is: can we still live in a developed society but also improve its sustainability by bringing back or integrate the daily physical activities? Can human-power be used to address excessive energy consumption and/or improve health and well-being of the society in more innovative way?

This paper starts with a literature review with a theoretical investigation of the benefits of human powered products. Arguments made by scholars in the field to outline different types of factors that are involved in understanding the benefit of using HPP are discussed. An experimental Home User Study to investigate the benefits of HPP is presented, where the change in behaviour of introducing this physical activity of using human-power are explored via condition of watching TV in a domestic environment. The findings of this work are discussed and analysed in the results and discussion section followed by the conclusion.

\section{Theoretical Investigation of the benefits of human-powered products}

\subsection{Direct benefits: financial benefit and environmental impact}

The cost factor may be a real driver when consumers decide to purchase a HPP. The amount of potential savings may work as a stimulus for their purchase or they may consider the size of the required contribution against the value of money invested. For example, running a 100 Watt TV for an hour will cost about an average of $£ 0.0145$ (based on $£ 0.145$ per $\mathrm{kWh}$ in the UK). This means the cost savings for applying human labour to power $1 \mathrm{~h}$ worth of TV watching will be equal to this figure. It can be argued that this is an insignificant benefit. However, in the case of using HPPs as replacement to battery running products, the cost benefit brings a different view due to further consumption of batteries. A study conducted by Jansen (1997) concludes that in between 1.4 to $2.9 \mathrm{y}$, the environmental impact of the battery powered radio will equal the value of human-powered radio; as known as 'break-even point' (Jansen, 2011).

Whilst recognising the potential of using human-power as alternative power for EuP, HPP should not solely be considered as battery replacement but also for the 'plug-in' power. It can be assumed that the increased use of HPP in household through substituting existing EuP will entail some incentives by being off the power grid. A quick simple calculation can be measured to predict the potential incentive size. For example, a report shows that the average in-use power consumption of table top/portable radio (DAB) measures at 2.04 Watt (MCMS, 2013). An average weekly listening hours per listener is $22.6 \mathrm{~h}$ (RAJAR, 2011). Therefore, 0.00204 ( $\mathrm{kW}$ of radio) $\times 22.6$ (average $\mathrm{h} / \mathrm{w}$ ) $\times 52$ (weeks in a year) $\times £ 0.145$ (average cost per kWh in UK) is equal to $£ 0.3476$. Therefore, it can be stated that the incentive of using HP Radio over the plugin power radio is compensated at a rate of saving of $£ 0.3476$ per year. If these figures are used in total life cycle cost, the average cost of the radio is approximately $£ 25$, when this is divided by 
$£ 0.3476$, it will require 72 years of consistent use of HP Radio to meet the 'break-even point' for the cost of ownership.

In speculating a 'break-even point' from environmental impact perspective, a comparative LCA study speculates that it will require 9.6 years of radio use to become a product that begins to 'give less environmental impact' within a life cycle scenario (Shin, 2014). The speculated benefits, both economic and ecological, discussed in this section may not imply to be a significant motivator. Also, the size of the incentives is very ambiguous, as well as the long break-even period of 9.6 years. This result indicate that the break-even period will likely to be insufficient to motivate users to purchase a HPP or consider it as a replacement to power plug-in devices; especially to gain any perceived financial benefits. The size of this benefit versus the user's amount of time and effort required to generate such benefit may seem incomprehensible. Therefore, purchasing or using such HPP cannot be seen as an efficient technology for the sole purpose of reducing electricity consumption or gaining the financial incentives. Nevertheless, it still brings attention to the emphasis on the element of 'design' which can potentially have an influence to bring the continuous demand-of-use or motivation towards sustaining the use of HPP.

\subsection{Intangible benefits: health and behaviour}

The acceptability of HPP may vary depending on different users' motivation and intentions towards using such products; for example, reducing the negative effect on the environment (Dean, 2008), caused by fossil fuel such as air pollution and global warming (Armaroli and Balzani, 2007). Not all users will purchase a HPP for the purpose of saving electricity consumption nor for the cost benefit intended for the reasons discussed above; the same way as cyclists are not all using their bikes to save fossil fuel consumption.

Measuring levels of these internal attitudes is very difficult since it relates to different variables. Moreover, there may be an issue of adoptability towards 'added discomfort' in the application of HPP (Jansen and Slob, 2003). In other words, feeling the 'physical fatigue' while exerting humanpower, although this fatigue may benefit some users with exercise in mind. For example, it is recognised that physical inactivity has a major effect worldwide, and elimination could improve the health substantially along with reducing the healthcare cost attributed to this unhealthy behaviour (Pratt et al., 2014). It is estimated that $6 \%$ of disease from coronary heart disease, $7 \%$ of type 2 diabetes, $10 \%$ of breast cancer and $10 \%$ of colon cancer are caused by physical inactivity (Lee et al., 2012). In 2002, it was extrapolated that the cost of disease which is directly attributable to physical inactivity was $£ 1.06 \mathrm{~b}$ in UK (Allender et al., 2007). It is assumed that insufficient participation of exercise and leisure related behaviours are becoming more sedentary as well as domestic and occupational activities. Statistics reported by British Heart Foundation 
show that $62 \%$ of men spent less than 1 h per week participating in sports and exercise, and $56 \%$ of women did not spend any time (Townsend et al., 2012).

This kind of lifestyle also undoubtedly contributes to decline in bodily health, and it is hard to accept that people in developed countries maintain their muscle tone by spending time in the gym rather than in their homes and gardens. A report shows that $15 \%$ of UK population pays an average membership fee of $£ 362$ to a health and fitness club per annum (MINTEL, 2007). Nevertheless, It has been reported from a 2007 Health Survey from England that people wanted to do more physical activity than they did at present; $66 \%$ for men and $69 \%$ for women (Craig and Shelton, 2008). High percentage of people, including children, in developed countries are becoming overweight or obese. This is mainly because physical activities are becoming more and more a luxury in a gymnasium or in sport activities rather than a necessity. More children spend more time playing video games and watching TV than doing outdoor or indoor physical activities. Therefore, for those who hold motives of exerting human-power in relation to obesity concerns and issue of suffering from physical inactivity, may gain benefits from using HPP. However, the actual external benefits gained from HPP use (e.g. saving occurred from generating own energy) unlikely to appeal as 'positive'. In other words, the potential financial savings from using HPP is unlikely to be justified as great motivation for HPP use. Moreover, it may expose the user of feeling 'double-loss' as both internal (e.g. physical fatigue) and external (e.g. relatively little saving) factors hinders the motivation for sustaining the HPP use.

From socio-psychological perspective, sustaining a particular behaviour through 'design' requires understanding of the complex system of practice. Yet, not enough empirical data is supporting these assumptions; however, it brings to a notion that relying on single external variable such as incentive is insufficient to bring an impact (Stern, 2000). Some may argue that increasing the external benefit that is giving a larger size of savings, could potentially overcome this barrier. Perhaps, an implementation of using additional psychological motives may alternatively influence on the determinants to sustain the use and possibly into a routine practice. These motivations may relate to the other variables such as health or overcoming obesity. In spite of HPP's low and to some extent disappointing value of incentive, it is not yet known how the actual users of HPP would value these incentives. If a product does not appropriately address, or its end results after use do not reflect the true desires, eventually the inadequate solutions will follow. D'Anna and Cascini (2016) emphasise that the effectiveness of goods and services of products within the Design for Sustainability has evolved far beyond simply bringing the eco-efficiency, and significant impact can be affected by design choices in respect to the influence in user's quality of life. In the case of HPP, people may favour the value for applying human-muscular energy as alternative to reduce the environmental impact caused by battery or grid power. However, it is still vital to understand what rationales are affecting the motivational determinants of using HPP. 


\subsection{The challenge in context - 'Physical-exercising' and HPPs}

Can we change the behaviour of people to make them 'earn' the luxury of using modern technologies in return of physical activities? If people must do a physical activity to enjoy modern technologies, regardless of being renewable energy or not, would that change their behaviour or allow them to be healthy? Would that make them more sustainable and force them to change behaviour and reduce their energy use? As discussed above, the Human-Powered Products (HPP) are not significantly practical in relation to energy or financial savings but it could be more attractive for health and well-being benefits.

A study seems necessary in understanding the actual consequences of using HPPs and how they might influence the user motivations towards their further use; especially in respect to adapting their use as an everyday energy source or as exercising device or as a controller of energy access. Shin and Bhamra (2016) emphasise that understanding the various forms of controlled motivation is highly essential in sustaining the use of HPP, and it solely relies on how the system of feedback interacts with the actual users. However, challenges still reside at developing more case studies to identify pertinent strategies that can transcend the obsolescence of an intervention. Therefore, this paper seeks to discuss these external determinants in a diverse perspective. An empirical study undertaken to investigate these assumptions and results obtained are discussed in subsequent sections.

\section{The Home User Study (HUS)}

\subsection{Methodology}

The case study was design to focused on the use of HPP in a domestic environment. This 'Home User Study' (HUS) is mainly aimed to investigate how potential users perceive the use of HPP as an energy source or as a controller of their energy use. Therefore, a new prototype, has been built and deployed to households for use. It has been found that a human-powered television is the most suitable device for the HUS. TVs are one of the largest electricity consuming appliances in the ICT sector. According to Bertoldi and Atanasiu (2007), TV manufactures have been introducing low power consuming TVs, but the number of TV ownership has continue to rise ever since, e.g. buying new and old TVs moved to a different room. More recent report also confirms the prolific increase of 'time spent watching TV' in the UK, particularly for children. Ofcom (2013) reported that people aged 4+ have spent an average of 241 minutes of TV watching per day in 2012, which is increased by 23 minutes from the year 2007. Moreover, concerns are raised over the fact that the third most popular activity carried out by people in Great Britain is watching TV or listening to music (Energy Saving Trust 2007). Eventually, the behaviour around TV watching 
contributes to 'Sedentary behaviour' as distinct from too little exercise. Veerman et al. (2012) argues that TV viewing time may be associated with a reduction of life expectancy that is comparable to other major chronic disease risk factors such as physical inactivity and obesity. So, there is an opportunity in bringing benefits that are beyond cost savings. Nevertheless, the major influence of selecting the TV device was based on the fact that larger output of HPP would have bigger impact on the determinants to sustain its use.

\subsection{The White Box}

The use of renewable energy directly to power any device could be problematic for using humanpowered products. This is because different devices would require different effort and people have different capabilities, including children, which makes the direct use of human-power a difficult task. To address this problem, the authors have developed a novel technology where the electrical device will still be powered from the mains but the human powered device will act as a relative energy measurement counter (i.e. energy controller) that can be calibrated based on the device or the user to get a reasonable effort for a reasonable period of time using the electrical device. Therefore, a novel device, called the 'White Box' (WB) was developed that links the physical activities (pedalling in this case) to the maximum energy that could be consumed by a device for a specific user. It uses a user scenario of using human-power as alternative to nonrenewable energy source and as a system to power the TV in use. Rather solely utilising the prototype as an instrument to draw discourse in understanding its adaptation, quantitative-driven data are extracted from monitoring unit installed in the prototype. During the period of use, this 'White Box' unit calculates total hours of TV watched, calories burned, distance travelled, and cost saved by being off the grid. These results should be seen as consequences of using humanpower as an everyday energy source that user may or may not accept as motivational value. With having a decision of powering a 'TV' via HPP, it has been required to build a prototype that meets the level of performance expected by study participants and developing a corresponding device.

\subsubsection{Role of feedback}

One of the most important aspect in the design the 'White Box' was the communication of feedback. Fischer (2008, p. 83) suggests three considerations that makes the feedback on energy consumption most effective:

- successfully captures the consumer's attention

- draws a close link between specific actions and their effects 
- activates various motives that may appeal to different consumer groups, such as cost savings, resource conservation, emissions reduction, competition, and others.

Literatures in the field implicates that feedback system or its interface must provide real-time (live) consequential information. For HPP, it is about knowing how much energy is being generating at the moment of interaction, and understanding the remaining available run-time. This avails the user to have much control over the pacing and timing of the power-generating interaction. However, the system of feedback in many HPPs have some obscure degree of interactivity in providing the consequential information. For instance, when HPP users are applying the human-energy (e.g. cranking or winding), in most cases the device uses a single LED as indication of 'charge'. However, during this kinetic interaction, users are not aware about how much of equivalent energy is being conserved. The consequential information, available time length of HPP use from charged electricity, is limited and users are not aware until the function stops to operate (see Figure 1).

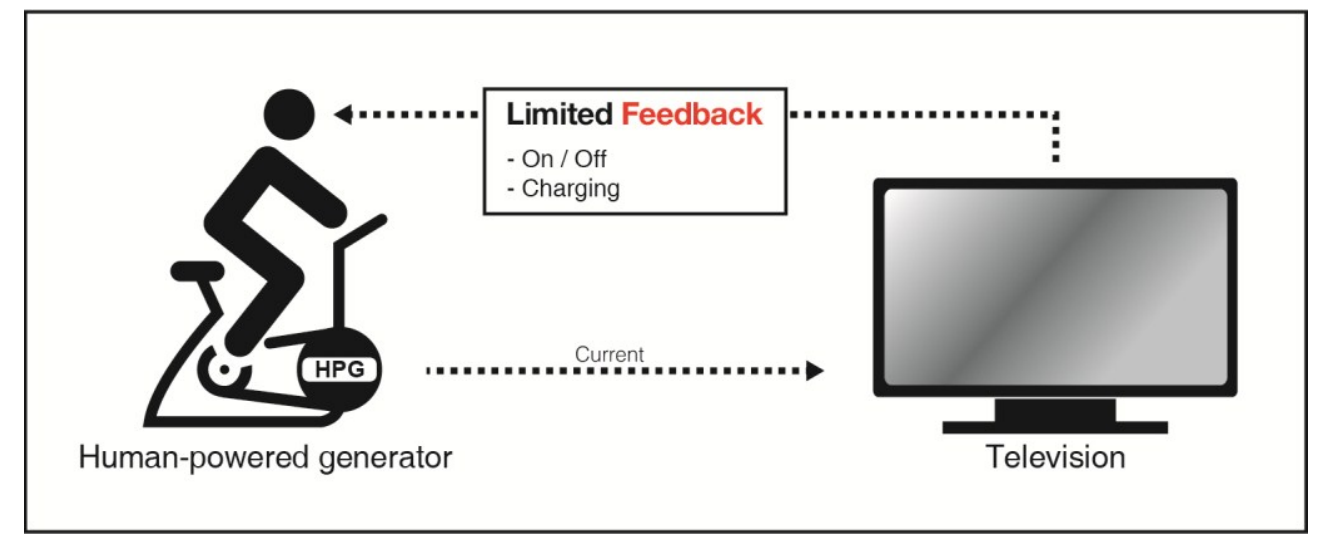

Figure 1: Diagram showing the limited feedback of current HPPs

Therefore, the 'White Box' prototype requires a new feedback interface. The purpose of this implementation is to enable the user to make certain goal-set through interacting with consequential information which is provided through the feedback system. More importantly, it is seen as a design strategy to link the subject of activity with the behavioural determinants. This notion is supported by scholars that when using the feedback as combined intervention with antecedent intervention such as goal-setting, the effectiveness of such intervention achieves better results in bringing about the change (Abrahamse et al., 2005); and comparing between daily and monthly feedback (Van Houwelingen and Van Raaij, 1989). Thus, the effectiveness of combined interventions depends on how well the feedback 
information is explained to the energy users. Moreover, it is hypothesised that extrinsic motivations can be controlled invariable to the extent to which they become self-determined as they enact the regulation (Deci and Ryan, 2000). However, it is important to keep in mind that these regulations can only be put in practice as people generate enough power to control and to set goals. The consequential information should be clearly visible, enabling the user to understand the link between their actions in order to activate various motives such as goal-setting. Figure 2 presents the diagram showing the concept of the desired and designed feedback system.

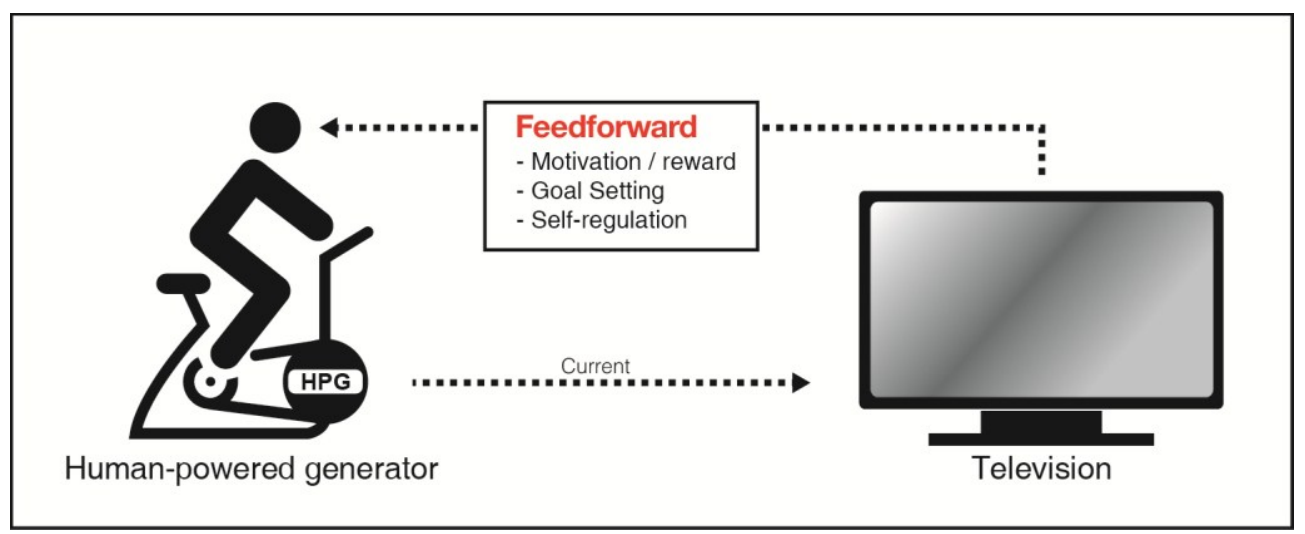

Figure 2: Diagram showing the concept of feedback system of the 'White Box'

The new prototype has two main components; the 'White Box' (energy controller unit) and the 'HPG' which stands for Human-Powered Generator, and in this case it is a cycling device. Figure 3 illustrates how the prototype operates. The user interface displays the real-time information of how much power is being generated and stored, but it can also simultaneously display the TV consumption rate. For example, as user exerts human muscular energy by pedalling the HPG, corresponding amount of charged energy is shown through the display in incremental unit count. However, as the user plugs in a TV adapter into the power inlet, which is located on the side panel and as the power current flows, the feedback display shows corresponding power loss in a decrementing count. As user continues to watch TV through stored energy, eventually the unit reaches 'zero'; then the input power to the TV is automatically switches off. Therefore, the TV switches off. Figure 4 presents the complete experimental system and the system in-situ in one of the homes. 


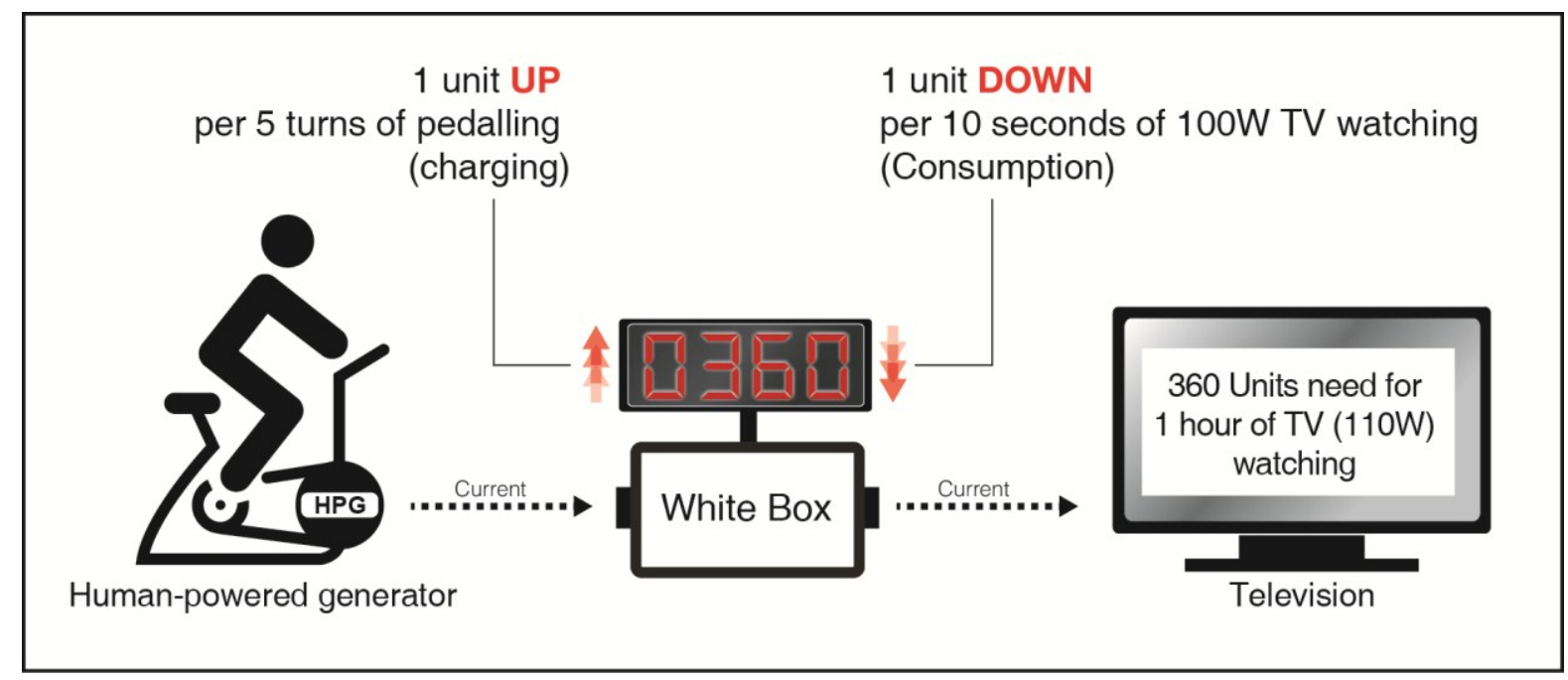

Figure 3: The charging and consumption rate of the proposed system

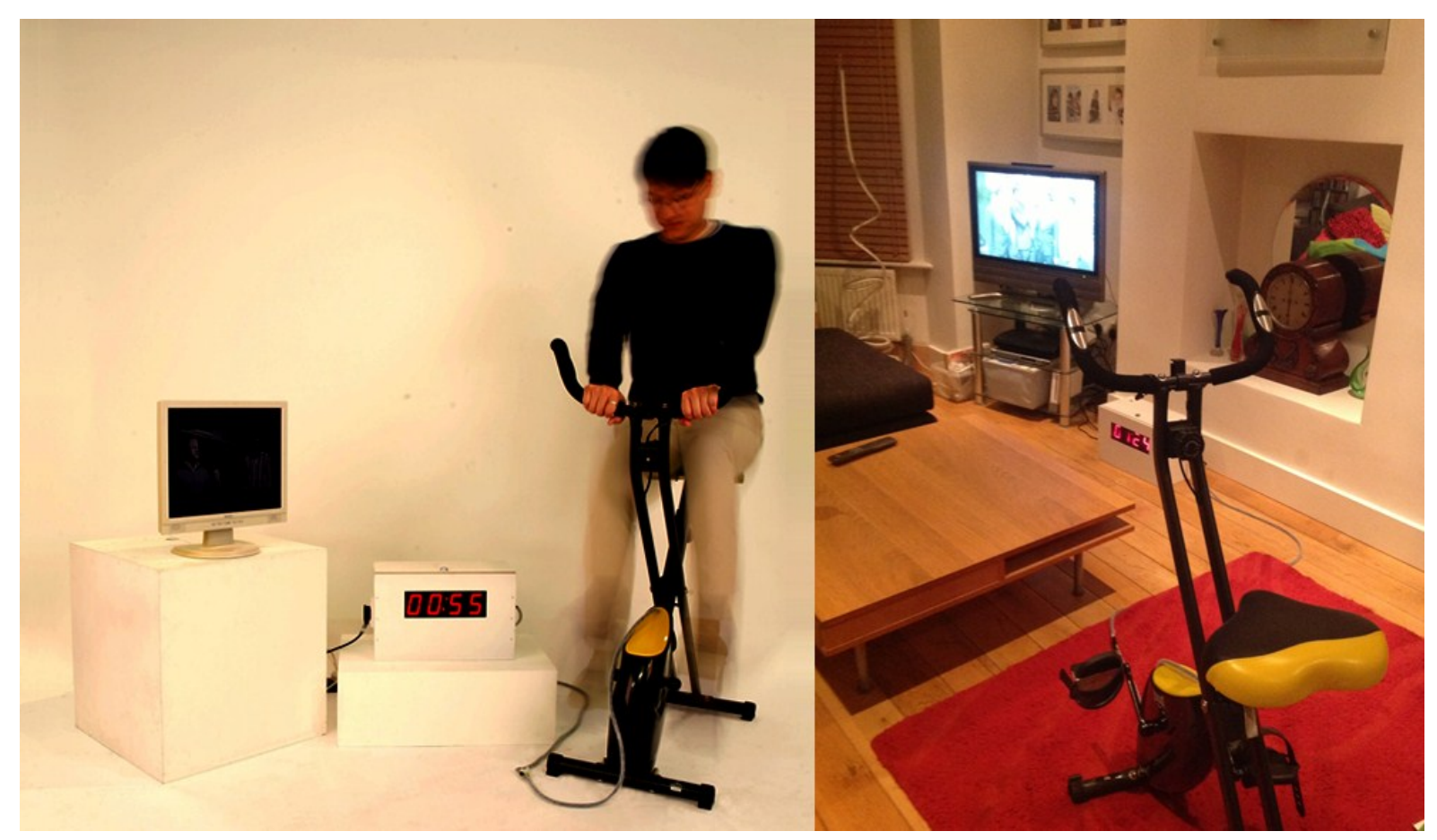

Figure 4: The designed HPG system (Left) and the deployment in situ (right).

\subsubsection{Human-Power Generator (HPG) performance}

In setting the maximum performance of HPG for powering the TV, consultations with experts in the field suggest that a person can power in between 100 to 300 Watt maximum. As a next step, 4 mixed gender volunteers have participated to measure the average pedalling count of the exercise bike for 30 minutes duration. This experiment has also measured that 5 pedal turns equal to 22 meter travelled, and 1 calorie burn. For measuring the consumption rate, the average TV consumption rate is averaged from the 405 TV brand listings which is measured at 110 Watt. 
However, the output of the HPG can vary upon user's pace of pedalling and the consumption rate of the television. In other words, the required pedalling time in generating the power needed for $1 \mathrm{~h}$ of TV watching can vary between approximately $1 / 2$ to an $1 \mathrm{~h}$. With these results, and through a number of revisions on the PCB design, the final ratio was set to: human-power input duration $(x \min )$ gives 110 Watt TV watching duration ( $2 x$ minutes).

In order to watch $1 \mathrm{~h}$ of a 110 Watt TV, the user on this system is required to exert 1800 pedalling turn counts which will increase the energy storage capacity up to 360 unit counts. It is worth noting that the aim of building the HPG prototype is not focused on achieving generator performance, nor design of battery system; but an instrument which enables the study to discover new knowledge and speculating the impact under a particular scenario. The Home User Study (HUS) has been scheduled for three visits at an interval of 1 week; visit 1 measuring their week TV usage; second visit - use of HPG and White Box; and visit 3 - follow up interview. A total of nine households are selected through a survey sampling process. On the first visit, a smart meter is placed to measure their average TV electricity consumption and the number of $\mathrm{h}$ of watching TV. These measurements are compared with data recorded by a monitoring unit of the White Box. The second visit took place a week after the first visit, deploying the White Box and the HPG in their home. A 'warm up' exercise guideline is given to household to avoid for any health and safety issues. The briefing started with demonstrating the power generation using the HPG. The results shown in this paper are collected at the final visit of the HUS.

\section{Results and discussion}

The average TV wattage measured from 9 households was 100 watts, which is closer to average wattage $(110 \mathrm{~W})$ set for the WB system. Depending on the TV wattage for each household, the time of pedalling varied. For example, a household had a TV consumption rate of 35 watts which would have given approximately 90 minutes of TV watching from 30 minutes of pedalling. Whereas, another household had wattage of 161 which would have given only 45 minutes of TV watching power from 30 minutes of pedalling.

\subsection{Environmental impact of HPG and White Box}

Identifying the various forms of benefit is important when understanding the true benefit of using HPP systems. Therefore, speculating the 'break-even point' for proposed HUS scenario has been vital. All parts of HPG system are dissembled and bill of material list (BOM) is created. Total number of parts are listed and these parts are analysed through SIMAPRO V.8.2.3 using Ecoinvent V.3.2 database, an LCA software, to measure their environmental impact value. The 
study used ReCiPe Endpoint (H) (V.1.12) Life Cycle Impact Assessment method (LCIA) to evaluate the environmental impact, which is expressed in units of points (Pts). The point is the total environmental impact or load expressed as a single score. In this point score, characterization, damage assessment, normalization and weighting are combined. The total environmental impact of the production of the HPG and the White Box is found to be 35.6 Pts, see Figure 5.

Additionally, it was assessed the environmental impact (EI) of the energy consumption (electricity) of the TV when powered by electricity from the grid. The data set for this rate is based on the assumption that the TV will be used in UK at consumption rate of $110 \mathrm{~W}$ (measured directly from the TV). According to meter measurement during HUS an average weekly hours per listener was $28 \mathrm{~h}$. This figure was multiplied by 48 (weeks) to get total hours per annum of use and multiplying by $0.11 \mathrm{kWh}$ which equals to $147.84 \mathrm{kWh}$ of consumption per annum. The environmental impact value of this electricity consumption from the grid was estimated at 8.26 Pts per annum.

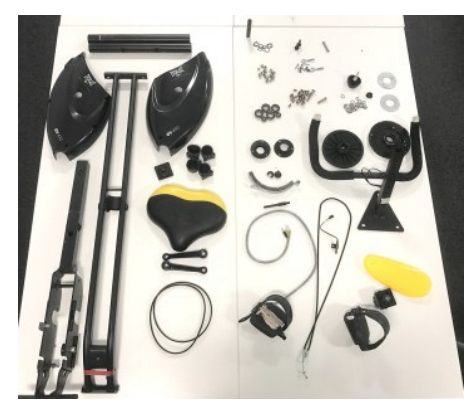

(a) Human Power Generator (HPG ) components
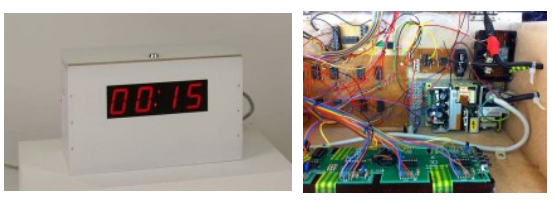

(b) White Box components

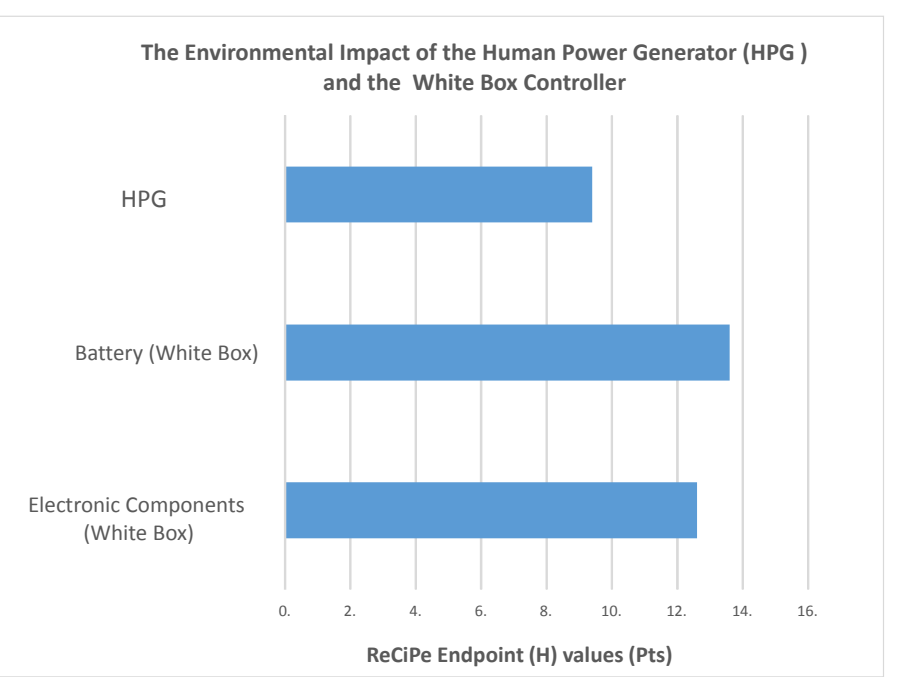

Figure 5: Environmental impact results of the production of the HPG and White Box, using ReCiPe Endpoint $(\mathrm{H})$ method. 
Break-Even Point of the Human-Powered Product (HPP) Including the Battery

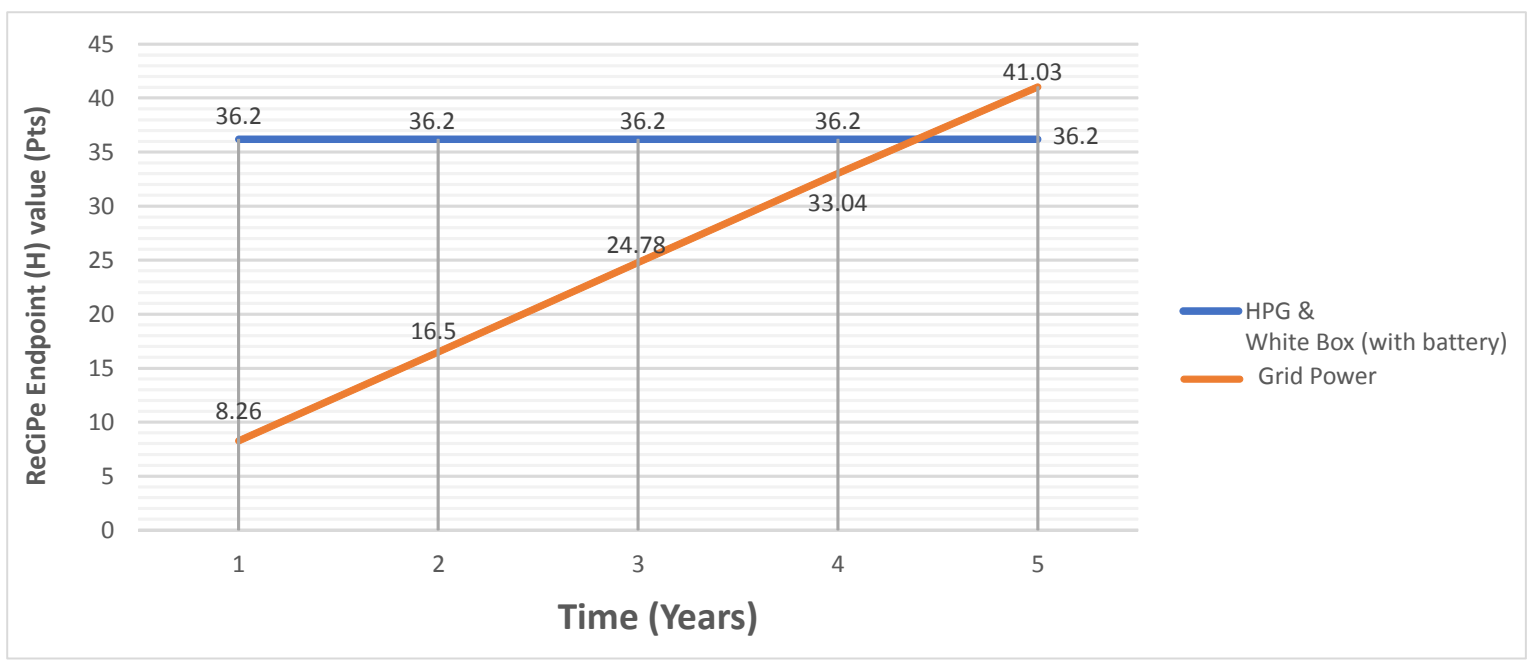

Figure 6: Environmental impact results of the HPG \& White box (with battery), and in comparison to the grid power over time (5 y) using ReCiPe Endpoint $(\mathrm{H})$ method.

Figure 6 illustrates the environmental impact in Pts of the HPG system and TV energy consumption over time, showing the 'break-even point'. The increasing Pts rate of the grid energy consumption will meet with the 'Environmental Impact value of the HPG system production' at $4.38 \mathrm{y}$, meaning it will require that amount of years to become a product that begins to 'give less environmental impact' within a life cycle scenario. Therefore, the time required to reach this 'break-even point' will vary depending on the types of HPP and its use scenario. Whilst recognising that lithium battery is the main contributor in increasing the Pts rate of HPG system, and speculating a scenario that HPG system will not store any power but run EuPs at direct input, the 'break-even' duration is reduced to $2.71 \mathrm{y}$ (See Figure 7 ). 


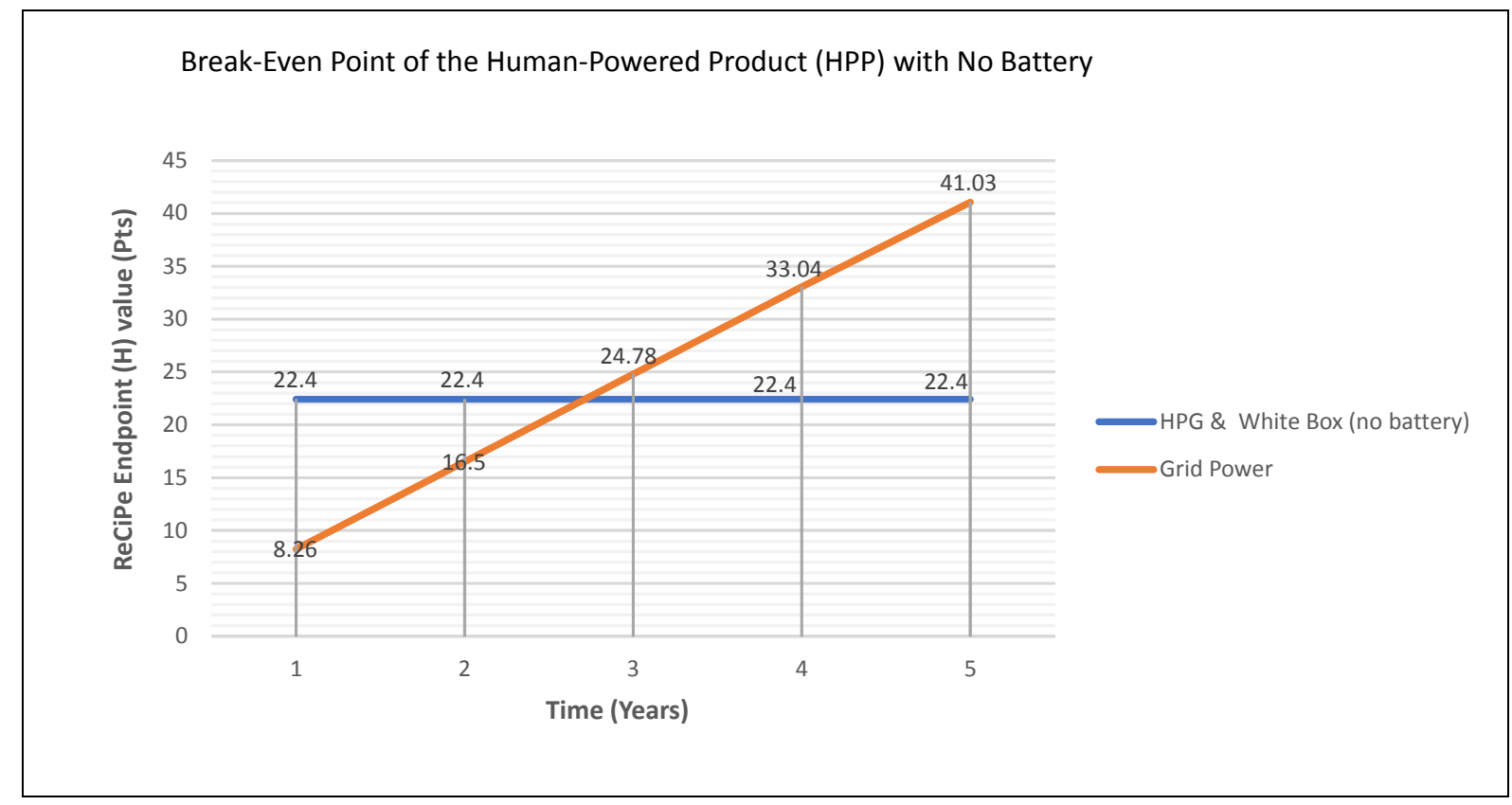

Figure 7: Environmental impact results of the HPG + White Box (without battery) and TV over time (5 y) using ReCiPe Endpoint $(\mathrm{H})$ method.

As has been pointed out above, these speculated durations for the 'break-even point' may not imply as a significant motivator for the purchase of HPPs. However, these results point to another notion that HPP systems should not only focus at bringing the increased efficiency but also how design should focus on the longevity of its use. In other words, approaches should not simply be reliant to applying technological solutions to reduce the duration reaching to 'breakeven point', but also consider how changes in behaviour during the use-phase can alternatively motivate to extend the lifecycle of intervention. Nevertheless, it can be argued that HPPs have an advantage in less developed countries where people have limited access to batteries or renewable energy or the grid power (electricity). In this situation, HPP will provide the viable means to power a TV, particularly if the cost of these energy sources are expensive.

\subsection{Change in sedentary behaviour}

When the system is experimentally tested in situ in the nine different houses as a Home User Study (HUS), only one household showed an increase of TV watching, whereas all 8 other household's TV usage time has decreased during the experimental work, see Figure 8 . The decreased amount ranged from a maximum of $4.37 \mathrm{~h}$ to a minimum of $0.4 \mathrm{~h} / \mathrm{d}$ (hours per day). Only Household number 4 increased their TV usage with an increase of $2.4 \mathrm{~h} / \mathrm{d}$. An average of 4.17 $\mathrm{h}$ of TV watching has been measured prior to HUS which is very close to statistics reported 
by Ofcom (2013) which is 241 minutes per day. However, during the HUS, it was measured that an average of TV watching hours has reduced to $2.66 \mathrm{~h}$ from all 9 households.

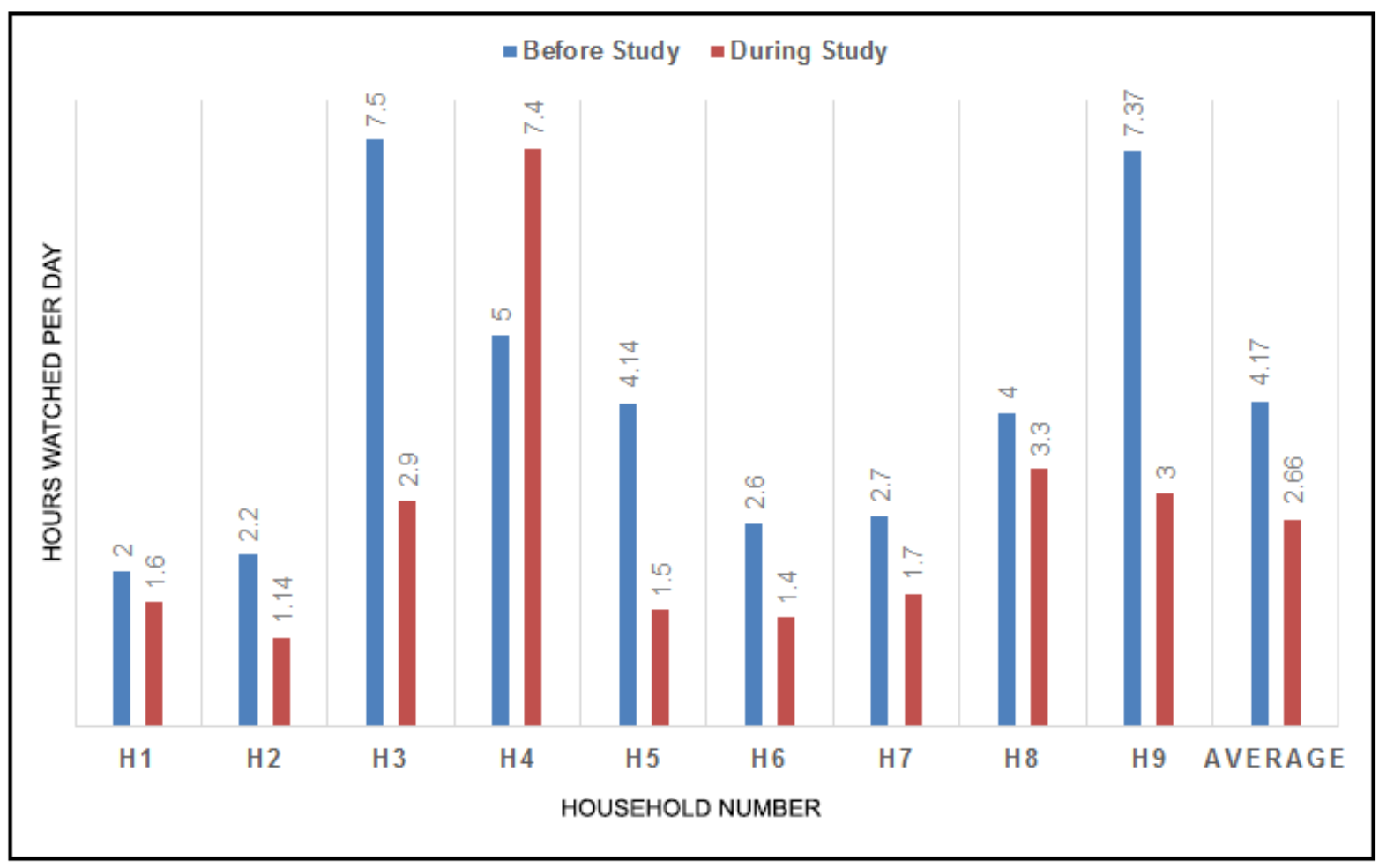

Figure 8: Total hours of TV watching per day by all households

The rationale for this change can be inadequate to ascertain as fact. However, it has been observed that behaviour such as using alternative entertainment device, using energy saving mode, and minimising the charge count loss through intermitted pattern of use (e.g. turning off during TV ads). However, the established fact is that all participants had to physically active to be able to watch TV.

\subsection{Change in energy consumption}

Due to all households having varied size of TVs, the consumption rate also differed. The amount of energy consumed during HUS was measured through the 'White Box'. An average of $3.2 \mathrm{kWh}$ of TV use was measured from all 9 households at the $1^{\text {st }}$ visit; and it reduced by 53 percent and measured at $1.5 \mathrm{kWh}$ average during HUS. 


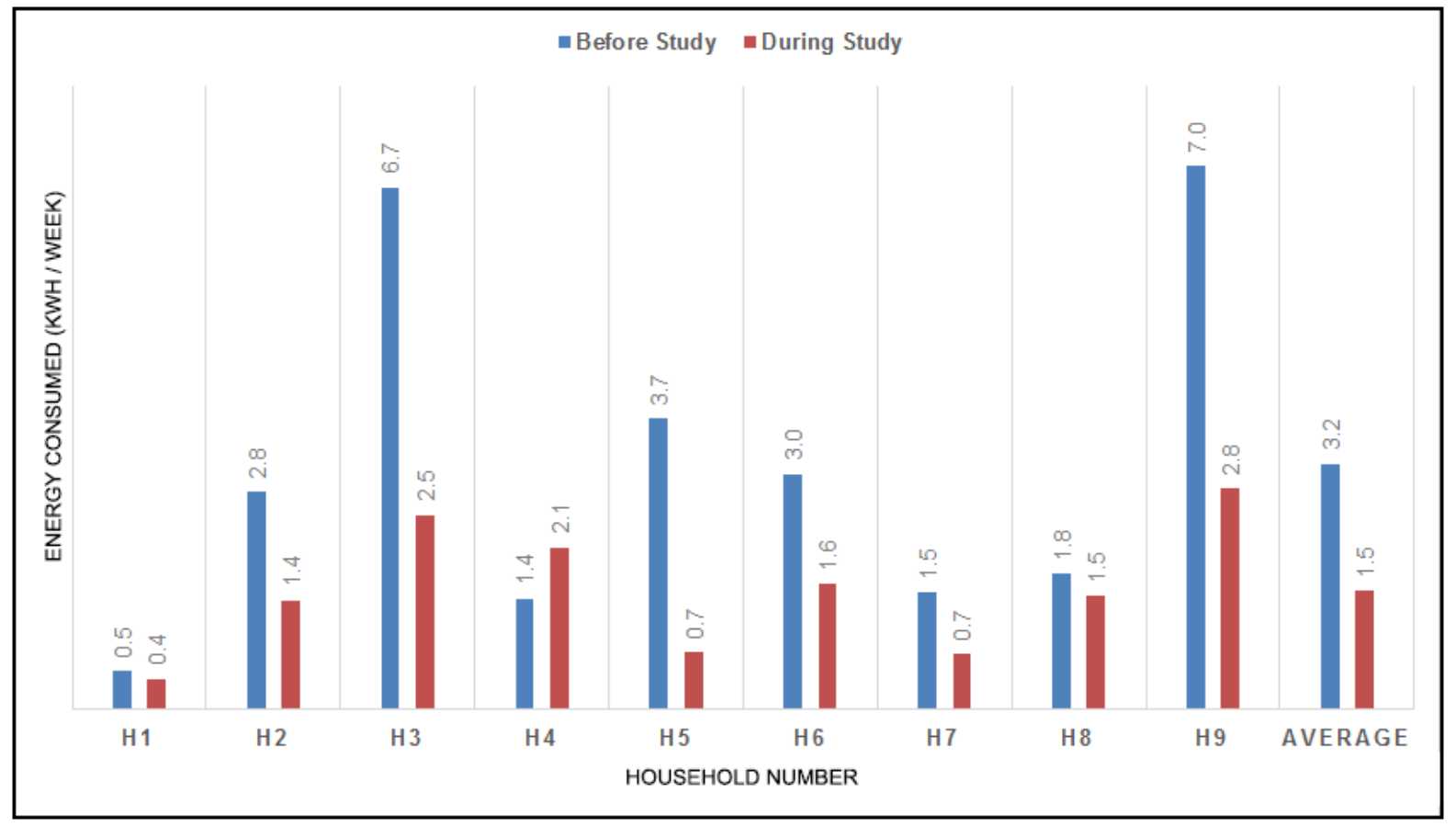

Figure 9: Energy consumed (Television) by all households

Whilst the changes in energy consumptoin shows a significant difference, the actual cost during HUS can be seen as insignificant. As expected, total energy cost saved during HUS can be perceived considerably low. An average of $£ 0.22$ is estimated per house and total incentive generated by all 9 households is summed as $£ 1.97$ (See Table 1).

Table 1: Total cost saved during HUS by all households

\begin{tabular}{|l|l|l|l|l|l|l|l|l|r|r|r|}
\hline Household & H1 & H2 & H3 & H4 & H5 & H6 & H7 & H8 & H9 & Average & \\
\hline Cost Saved & $£ 0.06$ & $£ 0.20$ & $£ 0.36$ & $£ 0.30$ & $£ 0.11$ & $£ 0.23$ & $£ 0.10$ & $£ 0.21$ & $£ 0.40$ & $£ 0.22$ & $£ 1.97$ \\
\hline \multicolumn{10}{|c|}{}
\end{tabular}

In relation to the financial payback period for a system cost of $£ 250$ pounds (HPG and white box), the system on average will produce $1.5 \mathrm{kwh}$ per week (78 kwh per year); for the cost of grid electricity of $£ 0.145$ per kWh, the yearly savings will be $£ 11.31$. Hence the economic payback period will be about 22 years.

However, on the other hand, a speculative calculation may give more weight to the numbers and helps to realise its potential when users of HP system increase. The value of totalled number can be interpreted in a different perspective by comparing with data presented in earlier sections. Consider the scenario of $1 \%$ of households in UK using this system for powering a TV, they will generate approximately $£ 30 \mathrm{M}$ of savings each year. However, all above figures define the 'external benefit' gained upon success adaptation of HPG on a daily basis, and this value 
may draw more resistance towards its further use. From individual perspective, this value may not be significant to maintain the use; but on the other hand, the value may appear as much greater when the number of users increases. Due to escalating price of energy, the savings and economic benefit would also have bigger impact in the future.

\subsection{The change in physical activity}

Another motivational value was the consequential data in relation to health. Total calories burned by all 9 participants have been measured as 55,322 calories and a total distance of 1218 kilometres is travelled. This distance is equal to a return road trip from London to Edinburgh.

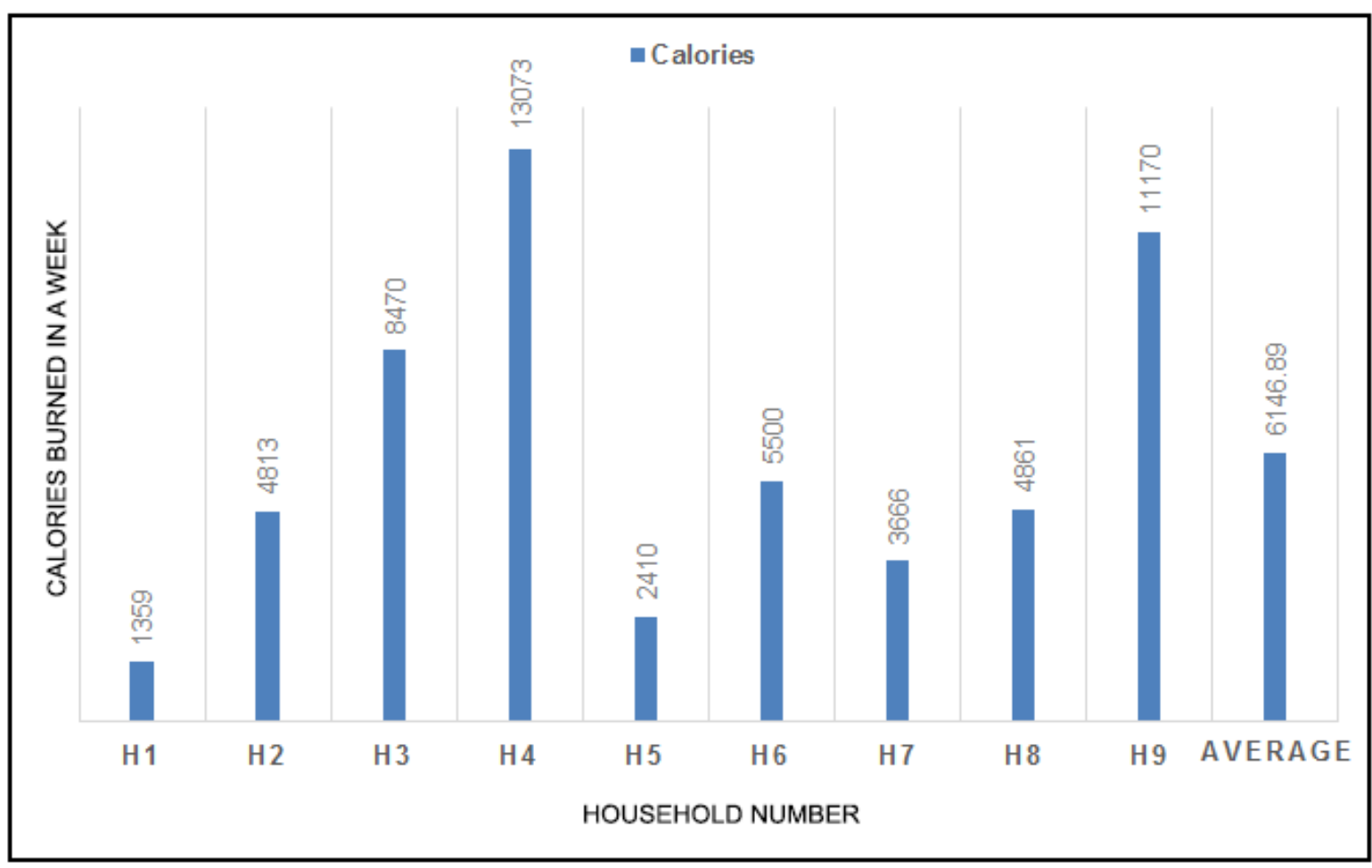

Figure 10: Total Calories burned during HUS by all households

Dean (2008) has provided a calculation that 380 calories are required to power 100 -watt colour TV for an hour. If the same calculation is used with this HUS data, this equals to 146 hours of TV running power generated by all households. To bring more attention to the value of these consequences, it is worth noting the serious concern over prevalence of lack of physical activities in the UK, and even worldwide. For example, an OECD report about increase of obesity estimates that seven of ten British people (70\%) will be overweight by 2020 (Sassi, 2010). If these individuals will use the human-powered TV for $1 \mathrm{~h} / \mathrm{d}$, it is estimated that $£ 244 \mathrm{M}$ can be saved each year while $£ 1.6 b$ is estimated to spend per year on overcoming the disease related to physical inactivity. To give another estimation, approximately $32 \%$ of adults spend $6 \mathrm{~h}$ of 
sedentary time on weekdays. If these individuals spend half of those sedentary time on exercising on an HPG, a cost of approximately £49M worth of electricity can be generated per year, but at the same time they can stay physically active. Physical activities can be related to weight loss (Swift et al., 2013); however, there are many other variables that influence the process such as food intake changes and age. It is normally easier to relate physical activities to other health benefits such as improving mental health, reducing risk of some diseases such as type 2 diabetes and high blood pressure and improving immune response, see for example (Miles, 2007).

Of course, the efficiency of storage unit and other many variables would affect these estimations. However, it emphasises on the potential impact of using human-power not only as an alternative energy but as a motivation in relation to public health and enhance physical activities. From the findings of this paper, it can be concluded that the human-power can be used to either generate renewable energy that would save some traditional energy from the grid or can be linked to an energy consumption controller (counter), where human physical activities are induced by the design of human-powered system. More specifically, the design of feedback system on HPP should enable the user to set a specific goal-directed patterns that leads to their motives related to financial or health. In either case, the system will entail the external benefits that can be a significant stimulus for continuative use; however, it depends on the effectiveness of the feedback system design.

\section{Conclusion}

This study is originated from setting the assumption that Human-Powered Products (HPPs) can bring gradual reduction of energy consumption by replacing the use of grid power. This concept is encouraged by the fact that household energy consumption has remained static, or increased over the past years, caused predominantly by the increase in the number of Energy using Products (EuP), especially due to the increase in electricity consumption from using consumer electronics and ICT related products.

The Life Cycle Assessment (LCA) analysis of the HPP use scenarios have indicated that cost savings are insignificant. and the HPPs are useful when batteries or grid electricity are not available. The presented experimental case study of Home User Study (HUS) attempted to challenge our existing routine of household energy use from 'take for granted' into physically 'work-for-it'. By considering the use of HPP as countermeasure for society's continuous lack of physical activities and its life-style, this paper has presented the entailing benefits in a diverse perspective. The paper outlined the benefits of bringing the perception of using human-power back to the original state where it can be seen as the 'norm'. Based on the findings, this paper has suggested an opportunity in the design of HPP that links energy and sustainability to public 
health via increasing physical activities. Many estimated benefits discussed in this paper could shed light on the benefit of using HPP. These benefits can encourage people to gradually increase physical activities and become healthy, particularly children, with potential energy savings from the use of HPP. Being physically active at home should reduce mental and physical illnesses and enhance quality of life. Future work will include additional case studies to assess the use of similar approach on the long term. Series of different feedback concepts will be tested; particularly focusing on children who lack daily sport activities and their behaviour when using digital entertainment devices.

\section{Acknowledgement}

The authors would like to acknowledge all participants of HUS, and technicians in at the School of Architecture Design and the Built Environment for their help in fabricating the test rig for this work.

\section{References}

Abrahamse, W., Steg, L., Vlek, C., Rothengatter, T., 2005. A review of intervention studies aimed at household energy conservation. Journal of Environmental Psychology 25 (3), 273-291.

Allender, S., Foster, C., Scarborough, P., Rayner, M., 2007. The burden of physical activityrelated ill health in the UK. Journal of epidemiology and community health 61 (4), 344-348.

Armaroli, N., Balzani, V., 2007. The future of energy supply: challenges and opportunities. Angewandte Chemie International Edition 46 (1-2), 52-66.

Bertoldi, P., Atanasiu, B., 2007. Electricity consumption and efficiency trends in the enlarged European Union. Institute for Environment and Sustainability. European Union.

Craig, R., Shelton, N., 2008. The Health Survey for England 2007 Volume 1: healthy lifestyles: knowledge, attitudes and behaviour. Leeds: The NHS Information Centre for health and social Care.

D'Anna, W., Cascini, G., 2016. Adding quality of life to design for Eco-Efficiency. Journal of Cleaner Production 112, 3211-3221.

Dean, T., 2008. The human-powered home choosing muscles over motors. New Society Publishers, Gabriola Island, B.C. 
DECC, 2011. Energy Consumption in the UK - Domestic Data Tables, in: Change, D.o.E.a.C. (Ed.). UK Statistics Authority, London, UK.

Deci, E.L., Ryan, R.M., 2000. The "What" and "Why" of Goal Pursuits: Human Needs and the Self-Determination of Behavior. Psychological Inquiry 11, 227-268.

Energy Saving Trust 2007. The Ampere Strikes Back. How Consumer Electronics are Taking Over the World, Energy Saving Trust, London, UK.

Fischer, C., 2008. Feedback on household electricity consumption: a tool for saving energy? Energy Efficiency 1, 79-104.

Jansen, A., 2011. Human Power empirically explored, Faculty of Industrial Design Enginering. Delft University of Technology, Delft, Netherland.

Jansen, A., Slob, A., 2003. Human power; comfortable one-hand cranking, in: al., F.A.e. (Ed.), ICED, International Conference on Engineering Design, Stockholm, Sweden.

Jansen, A., Stevels, A., 2006. Combining eco-design and user benefits from humanpowered energy systems, a win-win situation. Journal of Cleaner Production 14, 1299-1306.

Jansen, A.J., Ram, A.A.P. and Stevels, A.L.N., 1997. Renewable energy and the road towards 'green' portable audio products, in: Ritahuta (Ed.), ICED 1997, Tampere, Finland.

Jansen, A.J., Stevels, A.L.N., 1999. Human power, a sustainable option for electronics, Proceedings of the 1999 IEEE International Symposium on Electronics and the Environment. IEEE, pp. 215-218.

Jia, D., Liu, J., 2009. Human power-based energy harvesting strategies for mobile electronic devices. Frontiers of Energy and Power Engineering in China 3, 27-46.

Lee, I.-M., Shiroma, E.J., Lobelo, F., Puska, P., Blair, S.N., Katzmarzyk, P.T., 2012. Effect of physical inactivity on major non-communicable diseases worldwide: an analysis of burden of disease and life expectancy. The Lancet 380, 219-229.

Louie, H., Peng, K., Hoffstetter, E., Szablya, S.J., 2010. Design and testing of a small human-powered generator for developing rural communities, North American Power Symposium (NAPS), 2010. IEEE, pp. 1-8.

MCMS, 2013. Research study of energy consumptoin of digital radios, in: Department of Culture, M.S. (Ed.), London, UK. 
MINTEL, 2007. Health and Fitness Clubs, Leisure Intelligence. Mintel International, London, UK.

Ofcom, 2013. Communications Market Report 2013, London, UK.

Pandian, S.R., 2004. A human power conversion system based on children's play, Technology and Society, 2004. ISTAS '04. International Symposium on, pp. 54-61.

Pratt, M., Norris, J., Lobelo, F., Roux, L., Wang, G., 2014. The cost of physical inactivity: moving into the 21st century. British journal of sports medicine 48, 171-173.

RAJAR, 2011, Quarterly summary, period ending June 2011, Available at: http://www.rajar.co.uk/listening/quarterly listening.php

Rao, Y., McEachern, K.M., Arnold, D.P., 2014. A compact human-powered energy harvesting system. Energy Harvesting and Systems 1, 89-100.

Sassi, F., 2010. Obesity and the economics of prevention: fit not fat. Paris, OECD Publishing.

Shin, H.D., 2014. Switching the human-power back on: domesticating human-power to practice energy saving behaviour, School of Architecture Design and Built Environment. Nottingham Trent University, Nottingham, UK.

Shin, H.D., Bhamra, T., 2016. Design for sustainable behaviour: a case study of using human-power as an everyday energy source. Journal of Design Research 14, $280-$ 299.

Starner, T., 1996. Human-powered wearable computing. IBM systems Journal 35, 618-629.

Stern, P.C., 2000. New environmental theories: toward a coherent theory of environmentally significant behavior. Journal of social issues $56,407-424$.

Townsend, N., Bhatnagar, P., Wickramasinghe, K., Scarborough, P., Foster, C., Rayner, M., 2012. Physical activity statistics 2012. British Heart Foundation, London, UK.

Van Houwelingen, J.H., Van Raaij, W.F., 1989. The effect of goal-setting and daily electronic feedback on in-home energy use. Journal of consumer research, 98-105.

Veerman, J.L., Healy, G.N., Cobiac, L.J., Vos, T., Winkler, E.A.H., Owen, N., Dunstan, D.W., 2012. Television viewing time and reduced life expectancy: a life table analysis. British Journal of Sports Medicine 46, 927-930. 
